Egyptian Journal of Aquatic Biology \& Fisheries

Zoology Department, Faculty of Science,

Ain Shams University, Cairo, Egypt.

ISSN $1110-6131$

Vol. 23(5): 261 - 266 (2019)

www.ejabf.journals.ekb.eg

\title{
Antibacterial activity of silver nanoparticles biosynthesized using Spirulina platensis microalgae extract against oral pathogens
}

\author{
Sayed Rashad $^{1 *}$, Ghadir A. El-Chaghaby ${ }^{1}$ and Marwa A. Elchaghaby ${ }^{2}$ \\ 1- Regional Center for Food and Feed, Agricultural Research Center, Giza, Egypt \\ 2- Pediatric Dentistry and Dental Public Health department, Faculty of Dentistry, \\ Cairo University, Egypt \\ *Corresponding author: Sayed_rashad79@hotmail.com
}

\section{ARTICLE INFO \\ Article History: \\ Received: Dec. 2, 2019 \\ Accepted: Dec, 21, 2019 \\ Online: Dec. 24, 2019}

\section{Keywords:}

Silver

Nanoparticles

oral bacteria

Spirulina platensis

Streptococcus mutans

Staphylococcus aureus

Enterococcus faecalis

\begin{abstract}
In the present investigation, Spirulina platensis extract was used for biosynthesis of silver nanoparticles (AgNPs) and the antibacterial activity of the biosynthesized nanoparticles against oral pathogens was assessed. The biosynthesis of AgNPs was successfully achieved using $0.5 \mathrm{ml}$ of Spirulina extract and $50 \mathrm{ml}$ of silver nitrate $(1 \mathrm{mM})$ after 5 minutes of heating at $50^{\circ} \mathrm{C}$.

The formation of AgNPs was confirmed using UV- Visible spectrophotometer by the appearance of typical plasmon resonance band of AgNPs at $425 \mathrm{~nm}$. The average particle size of the biosynthesized AgNPs was $25.56 \mathrm{~nm}$. Three Gram positive oral bacteria were used to investigate the antibacterial activity of biosynthesized silver nanoparticles. These bacteria were Streptococcus mutans, Staphylococcus aureus and Enterococcus faecalis. The antibacterial activity was studied by determining the inhibition zone diameter using the disc diffusion method. The results showed that the AgNPs biosynthesized using Spirulina extract have good antibacterial activity against the three tested bacteria. The inhibition zone diameters were $12 \mathrm{~mm}, 12 \mathrm{~mm}$ and $13 \mathrm{~mm}$ for Streptococcus mutans, Staphylococcus aureus and Enterococcus faecalis, respectively. In conclusion, AgNPs biosynthesized using Spirulina platensis extract could be employed as antibacterial materials in dentistry. Further work could be addressed towards the optimization of the preparation conditions and controlling the size of nanoparticles.
\end{abstract}

\section{INTRODUCTION}

Microalgae research is increasingly attracting researchers' interest. Microalgae are infinite sources of various metabolites such as alkaloids, carbohydrates, flavanoids, pigments, phenols, saponins, steroids, tannins, terpenes and vitamins which possess several biotechnological and industrial applications (Guihéneuf et al., 2016). They are also enriched with several pharmacologically active compounds with antibacterial, anticancer, antifungal and antiviral activities. Several authors reported many beneficial applications of microalgae especially cyanobacteria in different aspects (Semary and Fouda, 2015; Vijayakumar and Menakha, 2015; Singh et al., 2017; Mostafa et al., 2019; Rashad et al. 2019). Spirulina platensis is a photosynthetic cyanobacteria with a plenty of nutritious compounds, phytochemicals, nutraceuticals and probiotics (Soni et al., 2017).

Nanoparticles have unique biological and optical properties which make them 
considered as efficient materials of the next technology generation with therapeutic and diagnostic applications. Metal nanoparticles are highly employed in a wide range of biomedical applications especially as antimicrobials (Saran et al., 2017). Silver ions and silver based compounds are known bactericides and have been extensively used in nanoparticles as antibacterial agents. Due to their large surface area that comes into contact with the microbial cells, the silver nanoparticles show effective antibacterial activity and thus have a higher percentage of interaction than larger particles of the same parent material (Patel et al., 2015; Salaheldin et al., 2019).

Silver nanoparticles are usually synthesized by chemical techniques thought their biosynthesis using extracts offers a worthy alternate. Biosynthetic methods employing either microorganisms or plant extracts have emerged as a simple and feasible alternative to chemical and physical synthetic procedures (Merin et al., 2010).

The application of nanoparticles in dentistry is of particular interest as the oral cavity frequently comes across a superfluity of microorganisms (Song and Ge, 2019). Among oral bacteria, Streptococcus mutans are Gram positive bacteria most frequently found in the oral cavity's normal flora (Azizi et al., 2015). They has been reported as a primary cariogenic bacterial pathogen due to their ability to metabolize different carbohydrates of sugar (Zhou et al., 2018). Saphylococcus aureus is also an abundant Gram-positive bacteria which has a strong connection to dental implant infections (Wang and Ren, 2017). Enterococcus faecalis has been connected to oral infections, such as caries, endodontic infections, periodontitis, and peri-implantitis (Komiyama et al., 2016). Controlling these bacteria is of utmost importance in dentistry. Thus, the present work aims to use Spirulina platensis extract for the biosynthesis of silver nanoparticles and to investigate the antibacterial activity of these nanoparticles against some oral bacterial pathogens.

\section{MATERIALS AND METHODS}

\section{Spirulina extract preparation}

Spirulina platensis was obtained in its dried powder form from the National Research Center, Egypt.

The extract was prepared as previously given by El-Chaghaby et al., (2019). Briefly, Spirulina powder was added to ethanol and the mixture was ultrasonicated for two hours at room temperature. The extract was then filtered using Wattman $\mathrm{N}^{\mathrm{o}} 1$ filter paper to obtain Spi-extract.

\section{Preparation of silver nitrate $(1 \mathrm{mM})$ solution}

Silver nitrate $\left(\mathrm{AgNO}_{3}\right)$ solution was prepared by dissolving $0.169 \mathrm{~g}$ of $\mathrm{AgNO}_{3}$ (Sigma, 99\%, 169.87g/mol) in 1 liter of deionized water.

\section{Biosynthesis of silver nanoparticles AgNPs}

The preparation of AgNPs using Spi-extract was achieved by drop wise addition of $0.5 \mathrm{ml}$ of Spi-extract to $50 \mathrm{ml}$ of $1 \mathrm{mM} \mathrm{AgNO}_{3}$ while stirring at $50^{\circ} \mathrm{C}$. The formation of AgNPs was monitored by visual transformation of the silver nitrate solution from colorless to yellow.

\section{Spectrophotometric measurements}

The formation of Ag nanoparticles was monitored by UV/ Vis spectrophotometer (SpecorD 250 plus, Analytik Jena).

\section{Particle size distribution}

Particles size distribution of $\mathrm{Ag}$ nanoparticles was determined by laser diffractometer using Zeta Sizer nano-series (Nano ZS). 


\section{Antibacterial activity of AgNPs}

The antibacterial activity of biosynthesized AgNPs was done using the disc diffusion method following the procedure described by Malabadi et al., (2012). The studied bacteria stains were Enterococcus faecalis, Staphylococcus aureus and Streptococcus mutans. The antibacterial tests were carried out at the Microbiology unit in the Microanalytical center, Cairo University.

\section{RESULTS AND DISCUSSION}

\section{Visual observations and UV-visible spectroscopy}

After 5 minutes of the addition of $0.5 \mathrm{ml}$ of spi-extract to the silver nitrate $(1 \mathrm{mM})$ solution and heating to $50^{\circ} \mathrm{C}$, the solution color changed from clear to yellowbrownish (Figure 1). This color change of the solution was taken as a first sign for the formation of silver nanoparticles.

The formation of silver nanoparticles (AgNPs) was further confirmed by spectral scanning over the wavelength range from 300 to $500 \mathrm{~nm}$ using UV-Vis spectrophotometer. As noted from Figure 2, the biosynthesized nanoparticles showed a maximum absorption peak at a wavelength of $425 \mathrm{~nm}$. Silver nanoparticles reveal remarkable optical properties directly connected to Localized Surface Plasmon Resonance (LSPR) which is highly dependent on the morphology of the nanoparticles (Veerasamy et al., 2011; Huang and Yang 2004).The typical plasmon resonance of AgNPs is confirmed by an absorption band in the range of $400-450 \mathrm{~nm}$.

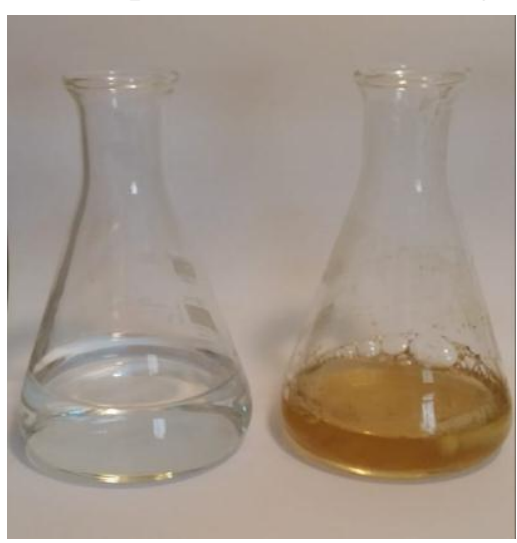

Fig. 1: Visual observation for the change in color of the reaction mixture

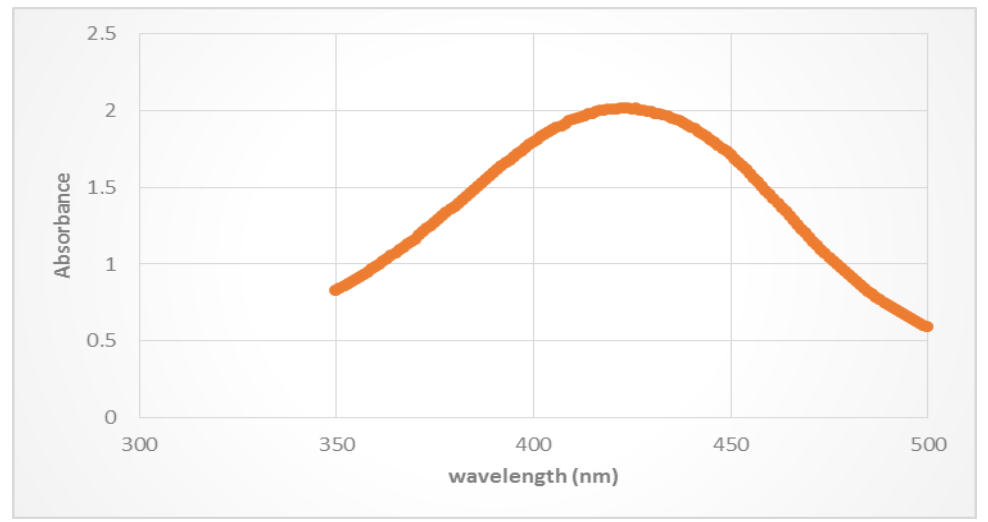

Fig. 2: UV-Vis absorption spectra of Spi-extract silver nanoparticles 


\section{Particle size distribution}

It is generally agreed that he size of nanoparticles has a major role affecting their different bioactivities. Figure 3 shows the particle size distribution of AgNPs biosynthesized using Spirulina extract. The average particle size was found to be equal to $25.56 \mathrm{~nm}$. The bioactivity of AgNPs is size-dependent and favors smaller particle size which is attributed to the relative increase of the surface area to volume ratio of nanoparticles and the contact surface area (Skandalis et al., 2017).

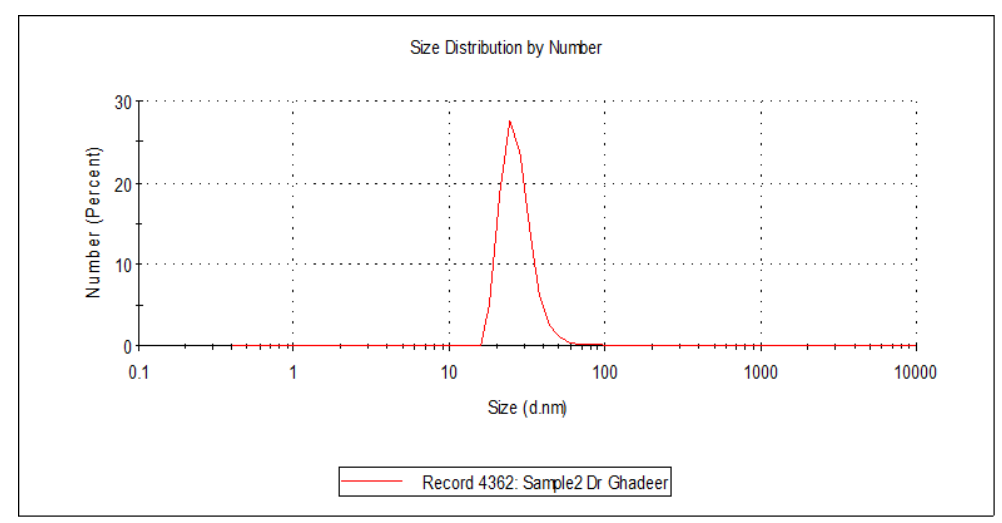

Fig. 3: Particle size distribution of biosynthesized silver nanoparticles

\section{Antimicrobial efficacies of biosynthesized nanoparticles}

Table (1) shows the results of antibacterial activity of silver nanoparticles biosynthesized using Spirulina extract. Streptococcus mutans and Staphylococcus aureus are key pathogens that cause infections concomitant with dental caries and dental implants (Wang and Ren, 2017). Enterococcus faecalis has been also related to oral diseases, such as caries, endodontic infections, periodontitis, and peri-implantitis (Komiyama et al., 2016). Thus, it is imperative to find ways for decreasing the bacterial burden of the oral cavity to prevent dental caries and other oral diseases (Wassel and Khattab, 2017). The results indicate that the AgNPs biosynthesized using Spirulina extract have good antibacterial activity against the three Gram positive oral pathogens Streptococcus mutans, Enterococcus faecalis and Staphylococcus aureus. The efficiency of the biosynthesized AgNPs against the tested bacteria could be attributed to the adherence of small sized AgNPs to the bacterial cell membrane surface and thus disturbing its permeability and respiration functions (Jagtap and Bapat, 2013).

Table 1: Antibacterial activity of AgNPs

\begin{tabular}{ll}
\hline Bacteria & Inhibition Zone diameter (mm) \\
\hline Streptococcus mutans & 12 \\
Staphylococcus aureus & 12 \\
Enterococcus faecalis & 13 \\
\hline
\end{tabular}

\section{CONCLUSION}

Spirulina platensis extract was used as a biomaterial for the biosynthesis of silver nanoparticles. The biosynthesized silver nanoparticles showed good inhibitory efficiency against three oral pathogens. These results propose the possibility of using such biosynthesized nanomaterial as antibacterial agent for dental applications. Further work could be addressed for investigating the mechanism of biosynthesis and to optimize it. 


\section{REFERENCES}

Azizi, A.; Aghayan, S.; Zaker, S.; Shakeri, M.; Entezari, N. and Lawaf, S. (2015). In vitro effect of zingiber officinale extract on growth of Streptococcus mutans and Streptococcus sanguinis. Int. J. Dent., 1-5.

El-Chaghaby, G.A.; Rashad, S.; Abdel-Kader, S.F.; Rawash, E-SA. and Abdul Moneem, M. (2019). Assessment of phytochemical components, proximate composition and antioxidant properties of Scenedesmus obliquus, Chlorella vulgaris and Spirulina platensis algae extracts. Egyptian Journal of Aquatic Biology \& Fisheries 23(4): 521 - 526.

Guihéneuf, F.; Khan, A. and Tran, L. S. P. (2016). Genetic engineering: a promising tool to engender physiological, biochemical, and molecular stress resilience in green microalgae. Front. Plant Sci., 7:400.

Huang, H. and Yang, X. (2004). Synthesis of polysaccharide-stabilized gold and silver nanoparticles: a green method, Carbohyd. Res., 339: 2627-2631.

Jagtap, U. B. and. Bapat, V. (2013). A Green synthesis of silver nanoparticles using Artocarpus heterophyllus Lam. seed extract and its antibacterial activity. Ind. Crops Prod., 46:132-137.

Komiyama, E. Y.; Lepesqueur, L.S.S.; Yassuda, C. G.; Samaranayake, L.P.; Parahitiyawa, N.B.; Balducci, I. and Koga-Ito, C.Y. (2016). Enterococcus species in the oral cavity: Prevalence, virulence factors and antimicrobial susceptibility. PLoS One, 11:1-11.

Malabadi, R.B.; Mulgund, G.S.; Meti, N.T. and Nataraja, K. (2012). Antibacterial activity of silver nanoparticles synthesized by using whole plant extracts of Clitoria ternatea. Research in Pharmacy. 2: 10-21.

Merin, D. D.; Prakash, S. and Bhimba, B.V. (2010). Antibacterial screening of silver nanoparticles synthesized by marine micro algae. Asian Pac. J. Trop. Med., 3:797-799.

Mostafa, S. S.; El-Hassanin, A.S.; Rashad, S.; Soliman A. Sh. and El-Chaghaby, G. A. (2019). Microalgae growth in effluents from olive oil industry for biomass production and decreasing phenolics content of wastewater. Egyptian Journal of Aquatic Biology \& Fisheries, 23(1): 359 -365.

Patel, V.; Berthold, D.; Puranik, P. and Gantar, M. (2015). Screening of cyanobacteria and microalgae for their ability to synthesize silver nanoparticles with antibacterial activity. Biotechnol. Rep., 5: 112-119.

Rashad, S.; El-Hassanin, A.S.; Mostafa, S.S.M. and El-Chaghaby, G.A. (2019). Cyanobacteria cultivation using olive milling wastewater for bio-fertilization of celery plant. Glob. J. Environ. Sci. Manag., 5: 167-174.

Salaheldin, T. A.; El-Chaghaby, G. A. and El-Sherbiny, M. (2019). Green synthesis of silver nanoparticles using Portulacaria afra plant extract: characterization and evaluation of its antibacterial, anticancer activities. Nov. Res. Microbiol J., $3: 215-222$.

Saran, S.; Sharma, G.; Kumar, M. and Ali, M.I. (2017). Biosynthesis of copper oxide nanoparticles using cyanobacteria spirulina platensis and its antibacterial activity. Int. J. Pharm Sci. Res., 8:3887-3892.

Semary, N. A. E. and Fouda, M. (2015). Anticancer activity of Cyanothece sp. strain extracts from Egypt: first record. Asian Pac. J. Trop. Biomed., 5: 992-995.

Singh, R.; Parihar, P.; Singh, M.; Bajguz, A.; Kumar, J.; Singh, S.; Singh, V.P. and Prasad, S.M. (2017). Uncovering potential applications of cyanobacteria and 
algal metabolites in biology, agriculture and medicine: Current status and future prospects. Front Microbiol, 8:1-37.

Skandalis, N.; Dimopoulou, A.; Georgopoulou, A.; Gallios, N.; Papadopoulos, D.; Tsipas, D.; Theologidis, I.; Michailidis, N. and Chatzinikolaidou, M. (2017). The effect of silver nanoparticles size, produced using plant extract from Arbutus unedo, on their antibacterial efficacy. Nanomaterials, 10:(7) 7.

Song, W. and Ge, S. (2019). Application of antimicrobial nanoparticles in dentistry. Molecules, 24:1-15.

Soni, R.A.; Sudhakar, K. and Rana, R.S. (2017). Spirulina - From growth to nutritional product: A review. Trends Food Sci. Technol., 69:157-171.

Veerasamy, R.; Xin, T. Z.; Gunasagaran, S.; Xiang, T. F. W.; Yang, E. F. C.; Jeyakumar, N. and Dhanaraj, S. A. (2011). Biosynthesis of silver nanoparticles using mangosteen leaf extract and evaluation of their antimicrobial activities. J. Saudi Chem. Soc., 15: 113-120

Vijayakumar, S., and Menakha, M. (2015). Pharmaceutical applications of cyanobacteriad. J. Acute Med., 5: 15-23.

Wang, H. and Ren, D. (2017). Controlling Streptococcus mutans and Staphylococcus aureus biofilms with direct current and chlorhexidine. AMB Express, 7.

Wassel, M.O. and Khattab, M.A. (2017). Antibacterial activity against Streptococcus mutans and inhibition of bacterial induced enamel demineralization of propolis, miswak, and chitosan nanoparticles based dental varnishes. J. Adv. Res., 8:387392.

Zhou, Y.; Millhouse, E.; Shaw, T.; Lappin, D.F.; Rajendran, R.; Bagg, J.; Lin, H. and Ramage, G. (2018). Evaluating Streptococcus mutans strain dependent characteristics in a polymicrobial biofilm community. Front Microbiol, 9: 1-10. 